\title{
Intimasi Pertemanan ditinjau dari Self-Disclosure pada Mahasiswa Jurusan Kebidanan Universitas Prima Indonesia
}

\section{Intimate Friendship Based on Self-Disclosure Among the Midwifery Students of Prima Indonesia University}

\author{
Sherly*, Sri Hartini \& Yulinda S. Manurung \\ Program Studi Psikologi, Fakultas Psikologi, Universitas Prima Indonesia
}

Diterima: Mei 2019; Disetujui: Juli 2019; Dipublish: Agustus2019

*Coresponding Email: taotaoo3011@gmail.com

\begin{abstract}
Abstrak
Penelitian ini berfokus untuk mengetahui hubungan antara self-disclosure dengan intimasi pertemanan. Hipotesis dalam penelitian ini adalah ada hubungan positif antara self-disclosure dengan intimasi pertemanan. Dengan asumsi semakin tinggi self-disclosure, maka semakin tinggi intimasi pertemanannya dan sebaliknya semakin rendah self-disclosure, maka semakin rendah intimasi pertemanan. Teknik pengambilan sampeldalam penelitian ini adalah purposive sampling. Subjek penelitian yang dipakai dalam penelitian ini adalah mahasiswa jurusan kebidanan di Universitas Prima Indonesia yang berjumlah 103 orang. Data diperoleh dari skala untuk mengukur self-disclosure dan intimasi pertemanan. Perhitungan dilakukan dengan melakukan uji prasyarat analisis (uji asumsi) yang berupa uji normalitas dan uji linearitas. Analisis data yang dipakai adalah menggunakan korelasi Product Moment melalui bantuan SPSS 25 for Windows. Hasil analisis data menunjukkan koefisien korelasi sebesar 0.731 dan nilai signifikansinya sebesar 0.000 ( $<<0.05$ ). Ini menunjukkan adanya hubungan positif antara self-disclosure dengan intimasi pertemanan. Hasil penelitian ini menunjukkan bahwa sumbangan yang diberikan variabel self-disclosure terhadap intimasi pertemanan sebesar 53.5 persen, selebihnya 46.5 persen dipengaruhi oleh faktor lain seperti kelekatan dan lamanya usia perkawinan. Dari hasil penelitian ini dapat ditarik kesimpulan bahwa hipotesis penelitian mengenai adanya hubungan positif antara self-disclosure dengan intimasi pertemanan dapat diterima.
\end{abstract}

Kata Kunci: Intimasi Pertemanan, Self-Disclosure

\begin{abstract}
This study aims to know the relationship between the intimate friendship with self-disclosure. The hypothesis in this study is there is a positive relationship between self-disclosure with intimate friendship, in assumption that the higher self-disclosure, the higher intimate friendship is and the lower selfdisclosure, then the lower intimate friendship itself. The subjects that used in this study are the midwifery students at the Prima Indonesia University, in which the population consists of 103 students. Data obtained from the scale to measure self-disclosure and intimate friendship. The calculation of the datas began by doing a test prerequisite analysis (the test of assumptions) that consists of a test of normality and a test of linearity. The data analysis in this study uses the Product Moment Correlation with SPSS 25 for Windows. The results of analysis showed the correlation coefficient at 0.731 of the significance $0.000(p<0.05)$. This shows there is a positive relationship between self-disclosure with intimate friendship. The results of this study indicate that the variable of intimate friendship can be predicted by self-disclosure at 53.5 percent and 46.5 percent of the rest are influenced by other factors which not examined in this study. Based on the results of this study, the hypothesis of there is a positive relationship between self-disclosure with intimate friendship is acceptable.
\end{abstract}

Keywords: Intimate Friendship, Self-Disclosure

How to Cite: Sherly. Hartini, S., \&Manurung, Y.S. (2019). Intimasi Pertemanan ditinjau dari Self-Disclosure pada Mahasiswa Jurusan Kebidanan Universitas Prima Indonesia. Journal of Education, Humaniora and Social Sciences (JEHSS). 2 (1): 36-46. 


\section{PENDAHULUAN}

Manusia sehari-harinya merupakan makhluk sosial yang selalu berhubungan dan membutuhkan bantuan dan kehadiran orang lain untuk berinteraksi. Sebagai makhluk sosial, manusia selalu berinteraksi dengan lingkungan tempat tinggalnyadalam setiap tingkah lakunya (Adler dalam Corey, 1986). Menjalin hubungan satu sama lain merupakan bagian yang tidak lepas dari kehidupan sehari-hari. Untuk itu dalam kehidupannya, manusia di sepanjang kehidupannya selalu berinteraksi dengan lingkungannya, misalnya dengan anggota keluarga, atau teman dan rekan kerja.

Hubungan sosial merupakan hubungan antar manusia. Hubungan sosial berupa jalinan interaksi antara keluarga, teman, atau sahabat, hingga masyakarat secara luas. Ada kalanya suatu hubungan mudah terjalin dan menyenangkan. Namun, tidak jarang pula orang memiliki hubungan yang sulit sehingga hubungan itu tidak menarik (Rakhmat, 2005). Hubungan sosial memiliki pola interaksi dimana tindakan dan katakataseseorang mempengaruhi orang lain memberikan tanggapannya. Seseorang akan berusaha untuk menyesuaikan diri antara apa yang dilakukan dan apa yang dikatakan, dengan reaksi yang terjadi, sehingga hubungan akan berkembang sepanjang waktu.

Teman mempunyai peran tersendiri dalam kehidupan sosial individu, yaitu hubungan interpersonal seperti dengan keluarga, rekan kerja, atau dengan sahabat. Faktor-faktor yang mempengaruhi hubungan pertemanan antara lain memilih dan menjalin pertemanan dengan orang lain, misalnya dari kesamaan sifat atau kesukaan, hobi, jarak rumah, orang tua, dan kemampuan mengelola emosi.

Menjalin pertemanan dalam kehidupan remaja tergambar dari tumbuh kembang mereka dengan pembentukan karakter diri yang terkadang tidak jauh berbeda dengan karakter dari teman yang sering berinteraksi dengannya. Ketika mulai beranjak remaja, orang tua tak lagi menjadi sosok panutan. Sepanjang rentang usianya, remaja akan menemukan jati dirinya dengan terlibat dalam hubungan pertemanan. Selain proses pencarian jati diri, proses pertemanan juga akan membantu individu lebih diterima dalam kehidupan sosialnya.

Pertemanan pada remaja yang terlalu terbuka mengenai perasaan dirinya kepada siapapun, dapat berakibat fatal kepada remaja tersebut. Seperti contoh kasus tindak kejahatan pada remaja dari perkenalan di dunia maya, kembali terjadi kepada seorang pelajar berinisial M (16 tahun), siswa kelas X sekolah menengah atas (SMA) menjadi 
korban penculikan yang dilakukan oleh AW (19 tahun), warga Jambe, Kabupaten Tangerang. Kepala Satuan Reskrim Kriminal Polres Jakarta Barat, Ajun Komisaris Besar Hengki Haryadi, mengatakan AW dan M berkenalan lewat situs jejaring sosial Facebook. Pelaku dan korban belum pernah bertatap muka selama dua tahun mereka berkenalan. "Mereka hanya berkomunikasi lewat Facebook," ucap Hengki di Polres Jakarta Barat, Senin, 25 Maret 2013 (www.tempo.co).

Pada Kamis, 21 Maret 2013, pelaku kemudian mengajak korban bertemu di kawasan Tenjo. Saat hendak bertemu pelaku, M pamitdengan alasan mengikuti kegiatan sekolah. "Namun sampai keesokan harinya M tidak pulang," kata Hengki. Orang tua korban melapor ke Polres Jakarta Barat pada Jumat pagi. Hengki menyebutkan selama pelaku pergi dengan korban, pelaku diam-diam mengirimkan pesan singkat kepada keluarga korban. Salah satunya meminta kepada keluarga korban mengirimkan uang sejumlah 200 juta rupiah. "Pelaku juga mengancam bila permintaannya tidak dipenuhi, ia akan menyiksa korban," ucap Hengki (www.tempo.co).

Berdasarkan hasil observasi dan wawancara yang dilakukan terhadap mahasiswa jurusan kebidanan di Universitas Prima Indonesia, terlihat bahwa kedekatan antar mahasiswa terjalin dengan baik, seperti terlihat bahwa mahasiswa terbagi menjadi kelompok-kelompok yang berisi teman-teman yang akrab dan sering terlihat bersama kemanapun mereka pergi. Selain itu, mereka juga sering terlibat dalam satu tugas kelompok yang sama, sehingga mereka merasa lebih nyaman bersama teman satu kelompok mereka dibandingkan dengan kelompok lain. Mereka juga mengaku sering keluar bersama-sama setiap akhir pekan, seperti berolahraga, berbelanja, nonton, dan nongkrong bersama. Mereka juga mengakui bahwa mereka sering saling curhat mengenai urusan pribadi mereka, seperti masalah dengan keluarga atau teman mereka yang lain. Namun, mereka hanya menceritakan masalah mereka kepada orang-orang yang mereka percaya dan yang dianggap dapat memberi umpan balik dari permasalahan yang mereka hadapi.

Dari sejumlah kasus di atas, dapat disimpulkan bahwa pertemanan merupakan hal yang penting dalam kehidupan remaja. Walaupun pertemanan pada remaja ini terkadang membawa dampak yang negatif, namun tidak jarang pula pertemanan pada remaja ini juga dapat membawa dampak yang positif bagi mereka. 
Intensitas pertemuan, jarak pertemanan, intimasi pertemanan merupakan aspek yang membedakan hubungan pertemanan antara teman yang satu dengan teman yang lain. Intimasi pertemanan sangat penting bagi remaja dan dewasa awal. Dikatakan bahwa sikap empati dan berbagi perasaan dengan orang lain, bersikap perhatian, saling percaya dan berkomitmen satu sama lain, mengungkapkan diri sendiri dan merawat teman, berhubungan dengan mengembangkan harga diri yang positif, penyesuaian diri yang lebih baik, dan merasakan identitas dirinya. Teori menempatkan intimasi pertemanan dengan teman sebaya dalam urutan perkembangannya, sebagai keterikatan dan kedekatan dengan sosok yang peduli, hubungan alami dengan orang tua, dan sebagai tahap perkembangan yang diikuti dengan formasi hubungan romantis (dalam Sharabany, 2008).

Faktor yang mempengaruhi intimasi pertemanan berdasarkan penelitian yang dilakukan Beyers dan Seiffge-Krenke (dalam Anggraeni, 2015), yaitu awal perkembangan diri, pencapaian identitas rasional, dan fungsi integratif dari identitas rasional. Selain itu, pendapat berbeda diungkapkan Hatfield dan Rapson (1994) yang mengungkapkan faktor yang mempengaruhi intimasi pertemanan adalah kepercayaan, komunikasi nonverbal, cinta dan kasih sayang (dalam Anggraeni, 2015).

Olforsky (dalam Suciati, 2015) mendefinisikan keintiman meliputi kemampuan untuk membentuk dan mempertahankan hubungan yang intim, yang biasanya terlihat dalam bentuk kedekatan, keterbukaan, komunikasi, tanggung jawab, hubungan timbal balik, komitmen, dan seksualitas. Kepuasan dalam hal ini bukan selalu diartikan sebagai hubungan seksual, tetapi lebih pada kepuasan dari individu dalam berinteraksi dengan orang lain.

Gary Campman (dalam Suciati, 2015) mengemukakan adanya lima aspek keintiman, yaitu keintiman intelektual, keintiman sosial, keintiman emosional, keintiman fisik, dan keintiman spiritual. Intimasi pertemanan seseorang dipengaruhi oleh keterbukaan antar sesama (self-disclosure) yang dibuktikan dari hasil penelitian oleh Manne, dkk. (2004) yang menyatakan bahwa ada hubungan signifikan antara selfdisclosure dan intimasi pada 98 wanita pengidap penyakit kanker beserta pasangannya.

Reis dan Patrick (1996) mengungkapkan bahwa self-disclosure adalah bagian penting dalam suatu proses interaksi intim dan mengembangkan hubungan intim, namun tidak sepenuhnya menangkap fenomena keintiman (dalam Perlman \& 
Vangelisti, 2006). Menurut Canary (dalam Taylor, dkk., 2006), self-disclosure adalah jenis percakapan khusus dimana kita berbagi informasi dan perasaan intim tentang diri sendiri dengan orang lain. Senada dengan Jourard (dalam Farber, 2006), mengartikan self-disclosure sebagai hak seseorang untuk diketahui orang lain.

Pentingnya self-disclosure terhadap intimasi juga didukung oleh penelitian oleh Laurenceau, dkk. (1998) menunjukkan bahwa ada hubungan positif dan signifikan antara self-disclosure dan intimasi pertemanan yang dilakukan pada 104 partisipan yang dipilih dari berbagai universitas, diantaranya 56 orang dari Universitas Massachusetts, dan 48 orang lainnya dari Universitas Pennsylvania.

Berdasarkan dari latar belakang yang dipaparkan, peneliti ingin melakukan penelitian untuk mengetahui hubungan intimasi pertemanan dengan self-disclosure pada mahasiswa jurusan kebidanan di Universitas Prima Indonesia. Adapun hipotesis penelitian yang diajukan adalah "Adanya hubungan positif antara self-disclosure dengan intimasi pertemanan", yang artinya semakin tinggi self-disclosure, maka intimasi pertemanan seseorang juga meningkat, sebaliknya jika self-disclosure rendah, maka intimasi pertemanan juga semakin rendah.

Hasil penelitian diharapkan dapat memberikan pandangan baru bagi dunia psikologi, khususnya psikologi perkembangan dan psikologi sosial. Selain itu, diharapkan juga dapat berguna bagi mahasiswa agar dapat mendorong mereka untuk meningkatkan intimasi pertemanan mereka terhadap teman-teman mereka melalui selfdislcosure yang baik, sehingga pertemanan mereka dapat berlangsung lama dan baik. Penelitian ini diharapkan dapat memberikan referensi kepada orang tua untuk mendidik anak-anak mereka agar menjadi pribadi yang baik dan dapat mengembangkan self-disclosure diri mereka sendiri.

\section{METODE PENELITIAN}

Variabel-variabel yang dipakai dalam penelitian adalah intimasi pertemanan sebagai variabel terikat dan self-disclosure sebagai variabel bebas. Subjek dalam penelitian adalah mahasiswa jurusan kebidanan Universitas Prima Indonesia. Jumlah subjek yang diambil dalam penelitian ini berjumlah 103 orang yang diambil dengan teknik purposive sampling yang merupakan teknik sampling yang berdasarkan pada 
kriteria tertentu. Adapun kriteria dari pengambilan subjek adalah terdaftar sebagai mahasiswa di Universitas Prima Indonesia dan merupakan mahasiswa fakultas keperawatan dan kebidanan terkhususnya jurusan kebidanan.

Alat pengumpulan data yang digunakan untuk mendapatkan data yang diperlukan adalah metode skala. Metode skala adalah metode yang menggunakan daftar pernyataan yang berisi aspek yang hendak diukur dan harus dijawab oleh subjek penelitian agar diperoleh ukuran yang lengkap dan tepat. Menurut Azwar (2014), skala dianggap menjadi alat yang tepat untuk mengumpulkan data karena berisi sejumlah pernyataan yang logis tentang pokok permasalahan dalam penelitian. Jenis skala yang digunakan adalah skala Likert dimana dalam skala ini memiliki pernyataan yang favorable (mendukung) dan unfavorable (tidak mendukung). Skala ini menggunakan 4 (empat) kategori jawaban, yaitu Sangat Setuju (SS), Setuju (S), Tidak Setuju (TS), dan Sangat Tidak Setuju (STS). Kriteria penilaian aitem favorable berdasarkan skala Likert adalah nilai (1) untuk jawaban Sangat Tidak Setuju (STS), nilai (2) untuk jawaban Tidak Setuju (TS), nilai (3) untuk jawaban Setuju (S), dan nilai (4) untuk jawaban Sangat Setuju (SS). Sedangkan kriteria penilaian untuk aitem unfavorable adalah nilai (1) untuk jawaban Sangat Setuju (SS), nilai (2) untuk jawaban Setuju (S), nilai (3) untuk jawaban Tidak Setuju (TS), dan nilai (4) untuk jawaban Sangat Tidak Setuju (STS). Teknik pengumpulan data penelitian ini dilakukan dengan cara pembagian skala.

Teknik analisis yang digunakan untuk menganalisis data hasil penelitian ini adalah dengan teknik korelasi Product Moment dari Pearson dengan menggunakan program SPSS 20 for Windows. Sebelum data-data dianalisa, terlebih dahulu dilakukan uji normalitas dan linieritas. Sebelum alat ukur dipakai, terlebih dahulu harus diukur tingkat validitas setiap butir dan reliabilitas alat ukur. Uji validitas dan reliabilitas yang dipakai dalam penelitian ini menggunakan rumus Corrected Item Total Correlation Alpha Cronbach dengan bantuan SPSS 20 for Windows.

\section{HASIL DAN PEMBAHASAN}

Berdasarkan hasil penelitian yang telah dilakukan, maka diperoleh hasil bahwa ada hubungan positif antara self-disclosure dengan intimasi pertemanan dengan koefisien korelasi Product Moment (Pearson Correlation) sebesar 0,731 dengan p sebesar 0,000 ( $<<0,05)$, artinya semakin tinggi self-disclosure, maka semakin tinggi 
intimasi pertemanan, atau sebaliknya semakin rendah self-disclosure, maka semakin rendah intimasi pertemanannya.

Pada penelitian ini diperoleh koefisien determinasi $R$ Square $\left(\mathrm{R}^{2}\right)$ sebesar 0.535 . Berdasarkan hasil tersebut dapat disimpulkan 53.5 persen intimasi pertemanan mempengaruhi self-disclosure pada mahasiswa jurusan kebidanan di Universitas Prima sedangkan 46.5 persen dipengaruhi oleh faktor lain. Adapun faktor lain yang turut mempengaruhi self-disclosure adalah kelekatan dan lamanya usia perkawinan.

Hasil penelitian yang menyatakan adanya hubungan positif antara intimasi pertemanan dengan self-disclosure sejalan dengan penelitian oleh Anggraeni, dkk., (2015) mengenai hubungan antara intimasi pertemanandengan self-disclosure pada 355 orang mahasiswa Universitas Negeri Yogyakarta stambuk 2012. Dengan hasil $\mathrm{R}^{2}=0.686$ dan $\mathrm{p}<0.000$, yang artinya ada hubungan positif dan signifikan antara intimasi pertemanan dan self-disclosure pada mahasiswa Universitas Negeri Yogyakarta stambuk 2012.

Penelitian ini juga menunjukkan rata-rata mahasiswa jurusan kebidanan di Universitas Prima Indonesia memiliki intimasi pertemanan yang tinggi, dimana dapat dilihat dari data penelitian yang menunjukkan tidak adanya mahasiswa yang dikategorikan memiliki intimasi pertemanan rendah, kemudian 39 orang mahasiswa dikategorikan memiliki intimasi pertemanan sedang dengan persentase 37.86 persen, dan 64 orang mahasiswa dengan persentase 62.14 persen dikategorikan memiliki intimasi pertemanan yang tinggi. Berdasarkan penjelasan di atas, dapat disimpulkan bahwa mahasiswa jurusan kebidanan di Universitas Prima Indonesia memiliki intimasi pertemanan yang tinggi.

Berdasarkan hasil observasi dan wawancara terhadap mahasiswa jurusan kebidanan di Universitas Prima Indonesia menunjukkan bahwa intimasi pertemanan dimiliki oleh semua mahasiswa. Hal ini dapat terlihat dari keintiman fisik yang terjadi seperti bergandengan tangan saat bersama dengan teman mereka. Selain itu, jika ada teman mereka yang sedang sedih, mereka juga tidak sungkan untuk memberikan pelukan hangat untuk menenangkan teman mereka yang sedang bersedih.

Selain itu berdasarkan hasil wawancara terhadap 39 orang mahasiswa atau 37.86 persen mahasiswa dengan tingkat intimasi pertemanan sedang, menunjukkan bahwa mereka terkadang merasakan ketidakcocokkan dengan teman mereka saat ini, seperti 
perbedaan pendapat. Namun jika mereka merasa kecocokkan dengan teman mereka saat ini, mereka akan merasa nyaman dengan teman mereka dan akan selalu mengajak satu sama lain untuk beraktifitas bersama. Salah satunya dengan pergi beribadah bersama, dan melakukan aktifitas sosial bersama di waktu senggang mereka.

Intimasi pertemanan yang tinggi dengan persentase 62.14 persen atau 64 orang mahasiswa, terlihat mereka kerap kali merasa dekat secara emosional dengan teman mereka, seperti turut berbahagia atas keberhasilan teman mereka, dan juga turut merasakan kesedihan atau penderitaan yang dialami teman mereka. Mereka juga seringkali berbagi pengalaman satu sama lain dan memberikan solusi dan tanggapan terhadap pengalaman mereka masing-masing. Selain itu mereka kerap berkomunikasi dan memberi kabar satu sama lain. Dengan demikian, kedekatan diantara mereka akan tetap terjalin dengan baik.

Penelitian ini juga menunjukkan rata-rata mahasiswa jurusan kebidanan di Universitas Prima Indonesia memiliki self-disclosure yang sedang. Hal ini dapat terlihat dari tidak adanya mahasiswa yang dikategorikan memiliki self-disclosure rendah, kemudian 58 orang mahasiswa dikategorikan memiliki self-disclosure sedang dengan persentase sebesar 56.31 persen, dan 45 orang mahasiswa memiliki self-disclosure yang tinggi dengan persentase 46.69 persen. Berdasarkan penjelasan di atas, dapat disimpulkan bahwa mahasiswa jurusan kebidanan di Universitas Prima Indonesia memiliki self-disclosure yang sedang.

Berdasarkan hasil observasi dan wawancara kepada mahasiswa jurusan kebidanan di Universitas Prima Indonesia menunjukkan bahwa self-disclosure dimiliki oleh seluruh mahasiswa. Hal ini dapat terlihat dimana mereka selalu memberi tanggapan kepada teman mereka bahkan tanpa diminta. Terlepas dari positif atau negatifnya tanggapan yang diberikan, mereka tetap memberikan tanggapan terhadap segala hal yang diungkapkan teman mreka.

Berdasarkan wawancara yang dilakukan kepada 58 orang mahasiswa atau 56.31 persen self-disclosure sedang, menunjukkan bahwa mereka saling bertukar informasi dan keinginan mereka tanpa berusaha menutup-nutupi atau memanipulasi informasi. Mereka dapat dengan leluasa mengungkapkan tentang diri mereka kecuali masalah di keluarga inti mereka. Mereka mengaku bahwa urusan keluarga lebih baik diselesaikan dengan keluarga mereka daripada menceritakannya kepada orang lain karena tidak 
ingin teman mereka ikut merasa cemas Bagi mereka, keterbukaan tentu saja penting, asalkan dalam konteks tertentu yang tidak terlalu bersifat privasi.

Self-disclosure tinggi pada 45 orang atau 46.69 persen terlihat dari beberapa mahasiswa yang sangat mudah mengungkapkan pendapat mereka di suatu diskusi. Mereka merasa bahwa mereka sering menjadi pencetus ide-ide cemerlang ketika berdiskusi bersama teman mereka. Sejalan dengan itu, mereka juga mudah mengungkapkan perasaan mereka dan bersikap apa adanya ketika bersama dengan teman mereka sehingga tidak adanya perasaan canggung diantara satu sama lain.

Berdasarkan penjelasan di atas, dapat disimpulkan tinggi rendahnya keterbukaan antar sesama dapat mempengaruhi keintiman yang terjalin di antaara mahasiswa. Merujuk pada pemaparan tersebut, maka dapat dikatakan bahwa ada hubungan positif antara self-disclosure dengan intimasi pertemanan di antara mahasiswa jurusan kebidanan di Universitas Prima Indonesia. Artinya semakin tinggi tingkat self-disclosure, maka semakin tinggi pula tingkat intimasi pertemanan yang terjalin. Sebaliknya, semakin rendah tingkat self-disclosure, maka semakin rendah juga tingkat intimasi pertemanan yang terjalin.

\section{SIMPULAN}

Dari hasil penelitian dalam penelitian ini, dapat disimpulkan adanya hubungan positif antara self-disclosure dengan intimasi pertemanan pada mahasiswa jurusan kebidanan di Universitas Prima Indonesia, dengan korelasi Product Moment (Pearson Correlation) (r) sebesar 0,731 dengan p sebesar 0,000 ( $\mathrm{p}<0,05)$, artinya semakin tinggi self-disclosure maka semakin tinggi intimasi pertemanan, atau sebaliknya jika semkain rendah self-disclosure maka semakin rendah intimasi pertemanan. Mean empirik dari intimasi pertemanan pada mahasiswa jurusan kebidanan di Universitas Prima Indonesia secara keseluruhan menunjukkan bahwa intimasi pertemanan subjek penelitian lebih tinggi daripada populasi umumnya. Hal ini terlihat dari mean empirik sebesar 73.81 yang lebih besar daripada mean hipotetik sebesar 60. Berdasarkan kategori, subjek yang memiliki intimasi pertemanan adalah sebanyak 0 orang atau 0 persen, subjek yang memiliki intimasi pertemanan sedang adalah sebanyak 39 orang atau 37.86 persen, dan subjek yang memiliki intimasi pertemanan tinggi adalah sebanyak 64 orang atau 62.14 persen. Mean empirik dari self-disclosure pada mahasiswa 
jurusan kebidanan di Universitas Prima Indonesia, secara keseluruhan menunjukkan bahwa self-disclosure subjek penelitian lebih tinggi daripada populasi umumnya. Hal ini terlihat dari nilai mean empirik sebesar 67.92 yang lebih besar daripada mean hipotetik sebesar 57.5. Berdasarkan kategori, subjek yang memiliki self-disclosure rendah adalah sebanyak 0 orang atau 0 persen, subjek yang memiliki self-disclosure sedang adalah sebanyak 58 orang atau 56.31 persen, dan subjek yang memiliki self-disclosure tinggi adalah sebanyak 45 orang atau 46.69 persen. Hasil penelitian juga menunjukkan sumbangan efektif yang diberikan variabel self-disclosure terhadap intimasi pertemanan adalah sebesar 53,5 persen, selebihnya 46,6 persen dipengaruhi oleh faktor lain yang tidak diteliti peneliti seperti kelekatan dan lamanya usia perkawinan.

\section{SIMPULAN}

Agusdwitanti, H., Tambunan, S. M., \& Retnaningsih. (2015). Kelekatan dan Intimasi pada Dewasa Awal. Jurnal Psikologi Vol. 8 No. 1 Hal 18 - 24. Diakses pada tanggal 17 Juli 2017 dari http://ejournal.gunadarma.ac.id/index.php/psiko/article/view/1286

Anggraeni, K. P. (2015). Hubungan Antara Self Disclosure dengan Intimasi Pertemanan pada Mahasiswa Universitas Negeri Yogyakarta Angkatan Tahun 2012. Artikel E-Jurnal Bimbingan dan Konseling. Edisi I, Tahun Ke-5. Diakses pada tanggal 17 Juli 2017 dari http://eprints.uny.ac.id/28870/

Azwar, S. (2006). Penyusunan Skala Psikologi. Edisi 1. Cetakan ke 8. Yogyakarta: Pustaka Pelajar.

Derlega, V. (1985). Self-disclosure and Intimate Relationships. In V. J. Derlega (Ed.), Communication, intimacy, and close relationships. New York: Academic Press.

Farber, B. A. (2006). Self-disclosure in Psychotheraphy. New York: The Guilford Press.

Indriastuti, I., \& Nawangsari, N. A. F. (2014). Perbedaan Cinta (Intimacy, Passion, Commitment) ditinjau dari Lamanya Usia Perkawinan pada Istri yang Bekerja. Jurnal Psikologi Industri dan Organisasi Vol. 3 No. 3 Hal 151 - 157. Diakses pada tanggal 21 Juli 2017 dari http://journal.unair.ac.id/JPIO@perbedaan-cinta-(intimacy,-passion,-commitment)-ditinjau-darilamanya-usia-perkawinan-pada-istri-yang-bekerja-article-8911-media-50-category-html

Laurenceau, J. P., Barret, L. F., \& Pietromonaco, R. P. (1998). Intimacy as an Interpersonal Process: The Importance of Self Disclosure, Partner Disclosure, and Perceived Partner Responsiveness in Interpersonal Exchanges. American Psychological Association Inc.: Journal of Personality and Social PsychologyVol. 74 No. 5 Hal 1238 - 1251. Diakses pada tanggal 20 Juli 2017 dari https://www.researchgate.net/publication/13685624_Intimacy_as_an_Interpersonal_Process_the_ Importance_of_Self_Disclosure_Partner_Disclosure_and_Perceived_Partner_Responsiveness_in_Inte rpersonal_Exchanges

Manne, S., Ostroff, J., Rini, C., Fox, K., Goldstein, L., \& Ganna, G. (2004). The Interpersonal Process Model of Intimacy: The Role of Self-Disclosure, Partner Disclosure, and Partner Responsiveness in Interaction Between Breast Cancer Patients and Their Partners. American Psychological Association Inc.: Journal of Family PsychologyVol. 18 No. 4 Hal 589 - 599. DOI: 10.1037/08933200.18.4.589. Diakses pada tanggal 20 Juli 2017 dari https://www/ncbi.nlm.nih.gov/m/pubmed/15598164/

Pearlman, D., \& Vangelisti, A. (2006). The Cambridge Handbook of Personal Relationship. New York: Cambridge University Press.

Priyatno, D. (2010). Paham Analisa Statistic Data dengan SPSS. Yogyakarta: Mediakom.

Rakhmat, J. (2005). Psikologi Komunikasi. Bandung: PT. Remaja Rosdakarya.

Sprecher, S. \& Hendrick, S. S. (2004). Self Disclosure in Intimate Relationships: Associations with Individual and Relationship Characteristics Over Time. Journal of Social and Clinical Psychology, Vol. 23 No. 6Hal857 - 877. Diakses pada tanggal 20 Juli 2017 dari https://guilfordjournals.com/doi/abs/10.1521/jscp.23.6.857.54803 
Suciati. 2015. Komunikasi Interpersonal: Sebuah Tinjauan Psikologis dan Perspektif Islam. Yogyakarta: Buku Litera.

Sugiyono. (2013). Metode Penelitian Pendidikan. Bandung: Alfabeta.

Taylor, S. E., Peplau, L. A., \& Sears, D. O. (2006). Social Psychology. Edisi ke-12. New Jersey: Pearson Education. 